\title{
Estudo anatômico comparado de órgãos vegetativos de boldo miúdo, Plectranthus ornatus Codd. e malvariço, Plectranthus amboinicus (Lour.) Spreng. - Lamiaceae
}

\author{
Claudia Mauro, ${ }^{*, 1,2}$ Celi de Paula Silva, ${ }^{2}$ Juliana Missima, ${ }^{2}$ Thiana Ohnuki, ${ }^{2}$ Renata B. \\ Rinaldi, ${ }^{2}$ Melissa Frota ${ }^{2}$ \\ ${ }^{1}$ Instituto Alberto Mesquita Camargo, Universidade São Judas Tadeu, Rua Taquari, 546, Mooca, 03166-000
São Paulo-SP, Brasil,
${ }^{2}$ Projeto Farmácia Viva, Faculdades Oswaldo Cruz, Rua Brigadeiro Galvão, 540, Barra Funda, 01151-000 \\ São Paulo-SP, Brasil
}

\begin{abstract}
RESUMO: Foi feita uma investigação anatômica dos órgãos vegetativos de Plectranthus ornatus, "boldo miúdo" e Plectranthus amboinicus, "malvariço", da família Lamiaceae. Foram estudados o limbo foliar, pecíolo e caule destas duas espécies. Ambas apresentam limbo foliar com tricomas tectores, com tricomas glandulares pedicelados em $P$. amboinicus e pedicelados e sésseis em $P$. ornatus. Justifica-se esta investigação, pelo fato de se tratar de espécies utilizadas, popularmente, como fitoterápico.
\end{abstract}

Unitermos: Plectranthus ornatus, Plectranthus amboinicus, Plectranthus L'Herit, Lamiaceae.

\begin{abstract}
Comparative anatomical study of the vegetative organs of boldo miúdo, Plectranthus ornatus Codd. and malvariço, Plectranthus amboinicus (Lour.) Spreng. Lamiaceae". An anatomical study of the vegetative organs of Plectranthus ornatus, "boldo miúdo" and Plectranthus amboinicus, "malvariço" was made. Both show non-glandular trichomes on the foliar leaf. In P. ornatus, there are pedunculate glandular trichomes and in P. amboinicus, sessile and pedunculate glandular trichomes. This study is justified by the popular utilization of both species as phytotherapeutic agents.
\end{abstract}

Keywords: Plectranthus ornatus, Plectranthus amboinicus, Plectranthus L'Herit, Lamiaceae.

\section{INTRODUÇÃO}

Os boldos pertencem a um grupo de espécies com propriedades colagogas. O verdadeiro boldo é o boldo do Chile, Peumus boldus Molina, que, no Brasil, é confundido com o falso boldo, Plectranthus barbatus Andr. Entre os boldos, os mais utilizados, popularmente, no Brasil, são o boldo do Chile, Peumus boldus Molina, o falso boldo, Plectranthus barbatus Andr. e o boldo baiano, Vernonia condensata Baker (Furlan, 1999; Morais et al., 2005; Agra et al., 2007 \& 2008). Na primeira Farmacopéia Brasileira, de 1929, a planta conhecida como "boldo" era o boldo do Chile; a diferenciação e correta identificação das espécies é importante, pelo fato do boldo do Chile e o falso boldo possuírem compostos que podem causar efeitos colaterais (Furlan, 1999; Brandão et al., 2006).

Representando a família Lamiaceae, como espécies do gênero Plectranthus, existem ainda o boldo miúdo, com atividade hepática, o malvariço ou malvasanta empregados como anti-séptico bucal e da garganta (Matos, 1998; Silva et al., 2006). Enquanto o falso boldo despertou muita atenção, devido à importância farmacológica atribuída aos diterpenos encontrados em suas folhas, relativamente poucas pesquisas existem sobre estas outras duas espécies do gênero Plectranthus L'Herit. Estudos anatômicos dos tricomas glandulares em folhas e flores de Plectranthus ornatus, foram conduzidos por Ascensão et al. (1999), que identificaram 5 tipos morfológicos deste tipo de tricoma, nesta espécie. Albuquerque et al. (2003), encontraram um novo diterpeno em folhas de P. ornatus, além da barbatusina, já descrita anteriormente em $P$. barbatus. Estes autores relatam a substituição do uso de boldo miúdo, no lugar do falso boldo, mesmo sem confirmação da atividade hiposecretora gástrica, em P. ornatus. Rijo et al. (2002) reportam o isolamento de 3 diterpenóides, semelhantes à forskolina, em folhas de $P$. ornatus, sendo que dois dos constituintes apresentam atividade antibacteriana. O malvariço é muito utilizado no norte do Brasil, para inflamações de boca e garganta (Albuquerque et al., 1990; Oliveira et al., 2007a); na medicina caseira, é utilizado para dores de garganta, tosse, bronquite e para o alívio de inflamações ovarianas e uterinas (Matos et 
al., 1988). Existem relatos de estudos farmacológicos e microbiológicos sobre $P$. amboinicus (Alvin Jose \& Janardhanan, 2005; Villate et al., 1999; Oliveira et al., 2007b). O presente trabalho tem como objetivo a descrição anatômica do limbo foliar, pecíolo e caule de Plectranthus ornatus e Plectranthus amboinicus, justificada pelo fato de serem espécies de utilização popular, no Brasil, como fitoterápico. Objetivou-se, ainda, o estabelecimento de correlações anatômicas entre as duas espécies.

\section{MATERIAL E MÉTODOS}

O material foi coletado no Horto Medicinal das Faculdades Oswaldo Cruz, localizado no campus da Faculdade Oswaldo Cruz, situado no bairro Barra Funda, em São Paulo, procedente de mudas obtidas do entreposto "Sabor de Fazenda". As duas espécies foram identificadas taxonomicamente pelo Prof. Dr. Marcos Roberto Furlan. Uma exsicata de cada material está depositada no Herbário do Instituto Horto Florestal de São Paulo, sob número 31270, para $P$. ornatus e 33196, para $P$. amboinicus. Para a fixação, utilizou-se F.A.A. [formaldeído $37 \%(\mathrm{v} / \mathrm{v})$ : ácido acético glacial: etanol $70 \%(\mathrm{v} / \mathrm{v}) ; 2: 1: 1]$, com posterior armazenamento em etanol $70 \%(\mathrm{v} / \mathrm{v})$. Para a descrição histológica, foram feitos cortes a mão livre, utilizando lâmina de barbear. O material foi clarificado em solução de hipoclorito de sódio $70 \%(\mathrm{v} / \mathrm{v})$ e submetido a coloração diferencial com azul de alcian $1 \%(\mathrm{p} / \mathrm{v})$ e fucsina básica $1 \%(\mathrm{p} / \mathrm{v})$. Cortes transversais e paradérmicos de limbo foliar e transversais de limbo, pecíolo e caule, foram montados em preparações semi-permanentes, em glicerina $50 \%(\mathrm{v} / \mathrm{v})$, com gotas de formalina e analisados em microscópio óptico binocular Coleman. As fotografias foram obtidas através de fotomicroscópio Karl Zeiss Jena, Jenamed 2 Histology.

\section{RESULTADOS}

I. Plectranthus ornatus Codd. (boldo miúdo, boldo chinês, boldinho, boldo rasteiro).Sinônimo Científico: Coleus comosus Hochst. Ex Guerke

\section{Descrição anatômica do limbo foliar}

O limbo foliar de P. ornatus, em corte transversal, apresenta uma epiderme unisseriada formada por células diminutas, muito compactadas, revestidas por uma cutícula lisa e espêssa. Há tricomas tectores unisseriados pluricelulares em abundância e tricomas glandulares pedicelados, em menor quantidade (Figuras 1 e 2). O mesofilo foliar é homogêneo ou isodiamétrico (Figura 2). Tricomas glandulares sésseis estão presentes, em quantidade relativamente menor que os pedicelados (Figuras 3 e 4)). Os estômatos, em vista paradérmica, pertencem ao tipo anomocítico e apresentam células- guarda reniformes (Figura 4), imersas em células epidérmicas de contorno sinuoso.

\section{Descrição anatômica do pecíolo}

O pecíolo de $P$. ornatus é revestido por uma epiderme unisseriada, revestida por uma cutícula espessa; sua secção é côncavo-convexa, em corte transversal. Há 2-3 camadas de colênquima angular, na porção cortical, abaixo da epiderme, bem como abundantes tricomas
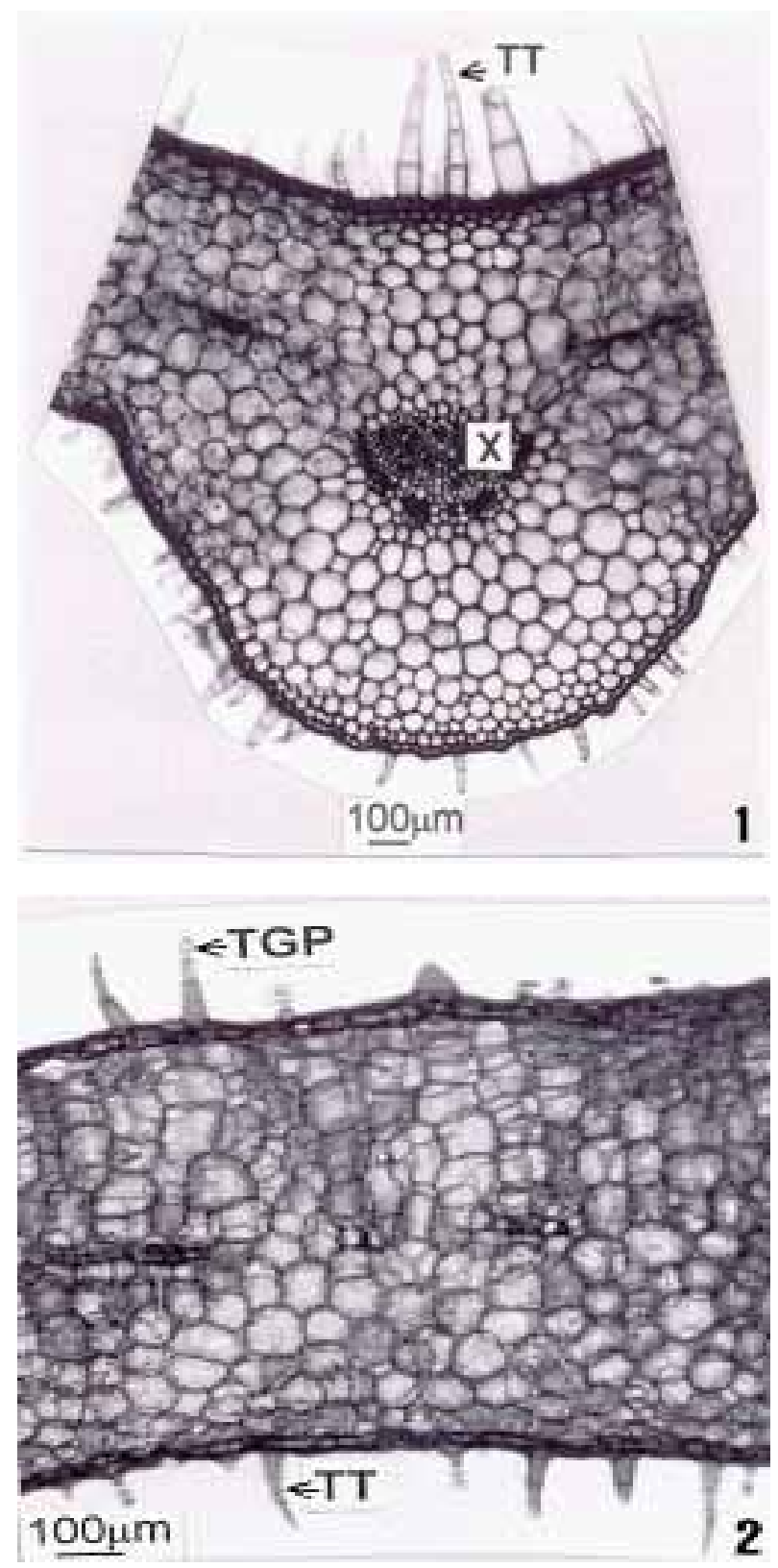

Figura 1. Boldo miúdo (Plectranthus ornatus Codd.). Secção transversal de limbo foliar, na altura na nervura central. TT: tricoma tector; X: xilema (elemento de vaso).

Figura 2. Boldo miúdo (Plectranthus ornatus Codd.). Secção transversal de limbo foliar, com mesofilo homogêneo isodiamétrico. TGP: tricoma glandular pedicelado; TT: tricoma tector. 

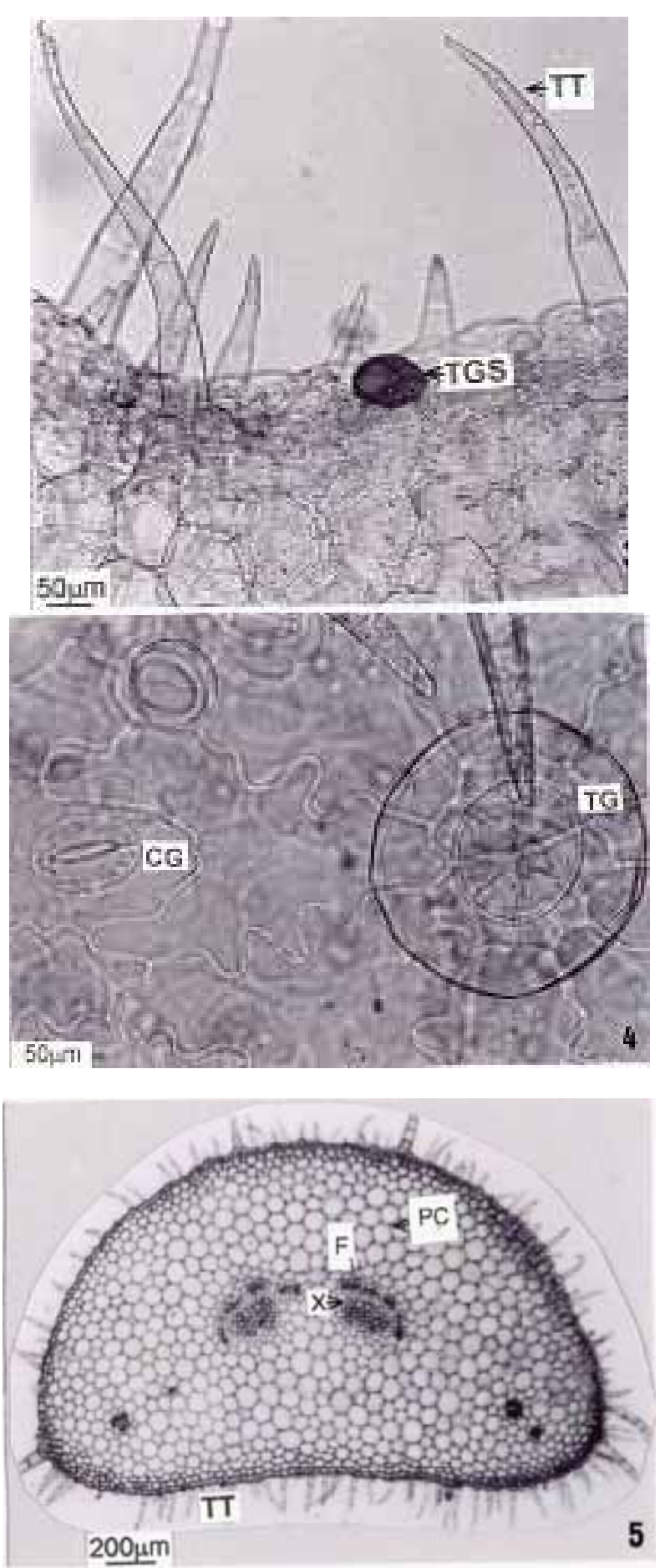

Figura 3. Boldo miúdo (Plectranthus ornatus Codd.). Secção transversal de limbo foliar. TGS: tricoma glandular séssil; TT: tricoma tector.

Figura 4. Boldo miúdo (Plectranthus ornatus Codd.). Secção paradérmica de limbo foliar. CG: célula guarda de estômato;

TG: tricoma glandular visto de cima.

Figura 5. Boldo miúdo (Plectranthus ornatus Codd.). Secção transversal de pecíolo. X: xilema (elemento de vaso). F: floema primário; PC: parênquima comum; TT: tricoma tector.
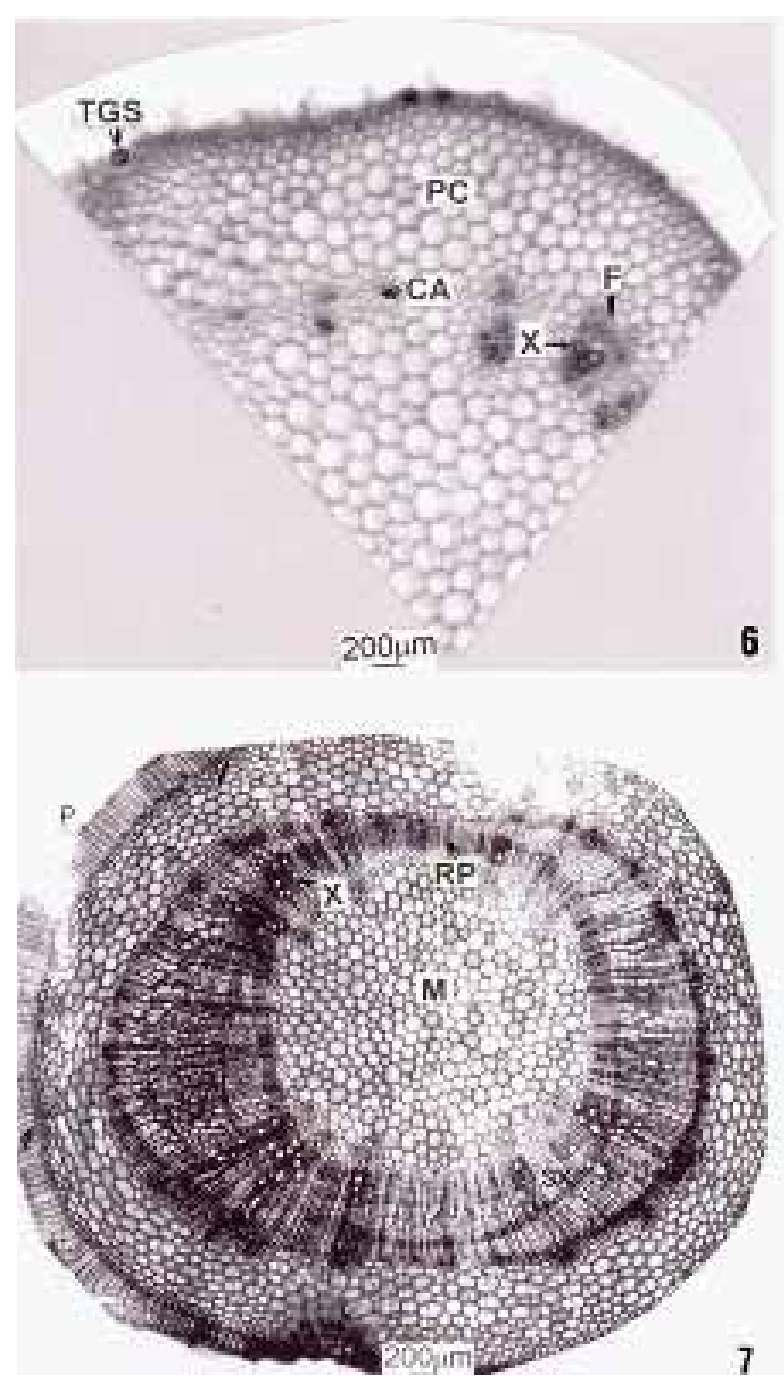

Figura 6. Boldo miúdo (Plectranthus ornatus Codd.). Secção transversal de caule em início de crescimento secundário. TGS: tricoma glandular séssil; PC: parênquima comum cortical; CA: câmbio; X: xilema (elemento de vaso); F: floema.

Figura 7. Boldo miúdo (Plectranthus ornatus Codd.). Secção transversal de caule. RP: raio de parênquima; X: xilema (elemento de vaso); M: medula parênquimática; P: periderme (súber).

tectores unisseriados pluricelulares (Figura 5). O feixe vascular é colateral fechado, com 2 feixes menores nas 2 extremidades (Figura 5). A região cortical apresentase rodeada por parênquima homogêneo isodiamétrico; há colênquima angular abaixo da epiderme (Figura 5).

\section{Descrição anatômica do caule}

O caule é revestido por uma epiderme unisseriada, com tricomas tectores em caules jovens (Figura 6). Evidenciou-se parênquima comum com meatos nas regiões cortical e medular. Não foram visualizados cristais de oxalato de cálcio. $\mathrm{O}$ caule em 

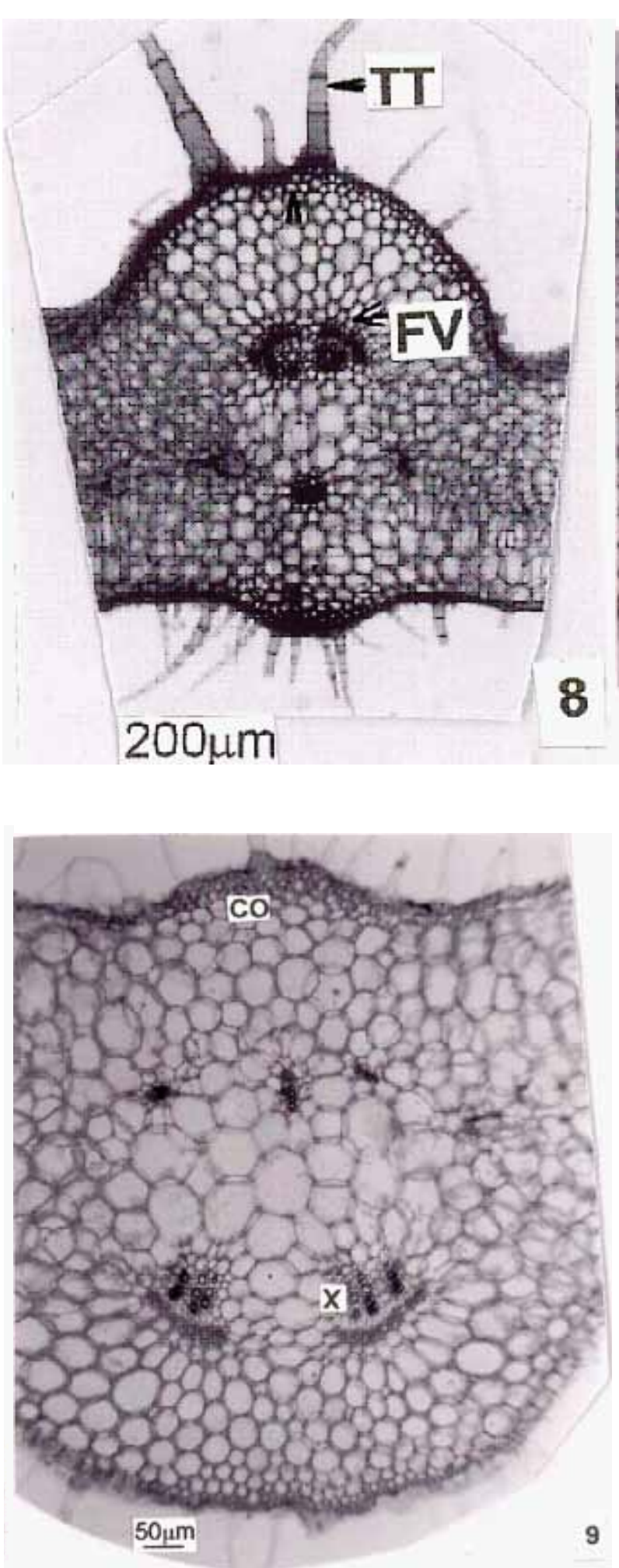

Figura 8. Malvariço (Plectranthus amboinicus (Lour.) Spreng.). Secção transversal de limbo foliar: nervura central. TT: tricoma tector; FV: feixe vascular.

Figura 9. Malvariço (Plectranthus amboinicus (Lour.) Spreng.). Secção transversal de limbo: detalhe da nervura central. X xilema (elemento de vaso); CO: colênquima.
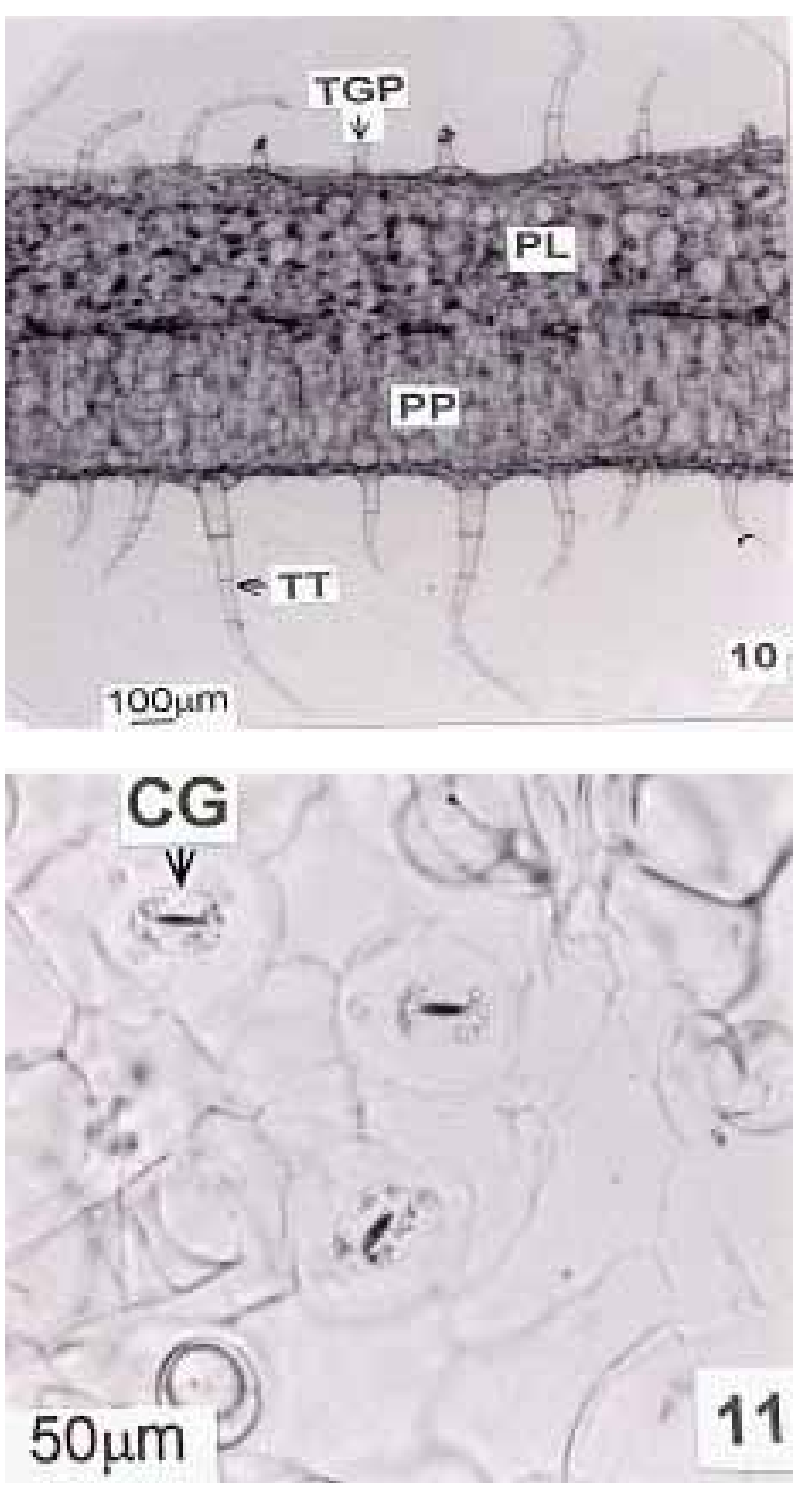

Figura 10. Malvariço(Plectranthus amboinicus (Lour.) Spreng.). Secção transversal de limbo foliar: mesofilo dorsiventral. PP: parênquima paliçádico; PL: parênquima lacunoso; TT: tricoma tector; TGP: tricoma glandular pedunculado.

Figura 11. Malvariço (Plectranthus amboinicus (Lour.) Spreng.). Corte paradérmico de limbo foliar. CG: célula guarda de estômato.

estrutura secundária mostra um xilema secundário bem desenvolvido, formado por abundantes fibras esclerenquimáticas e relativamente poucos elementos de vaso (Figura 7). Existem poucas fibras de esclerênquima de floema primário, nesta estrutura.

II. Plectranthus amboinicus (Lour.) Spreng. (hortelãgorda, hortelã-pimenta, malvarisco). Sinonímia científica: Coleus amboinicus Lour., Coleus aromaticus Benth.

\section{Descrição anatômica do limbo foliar}



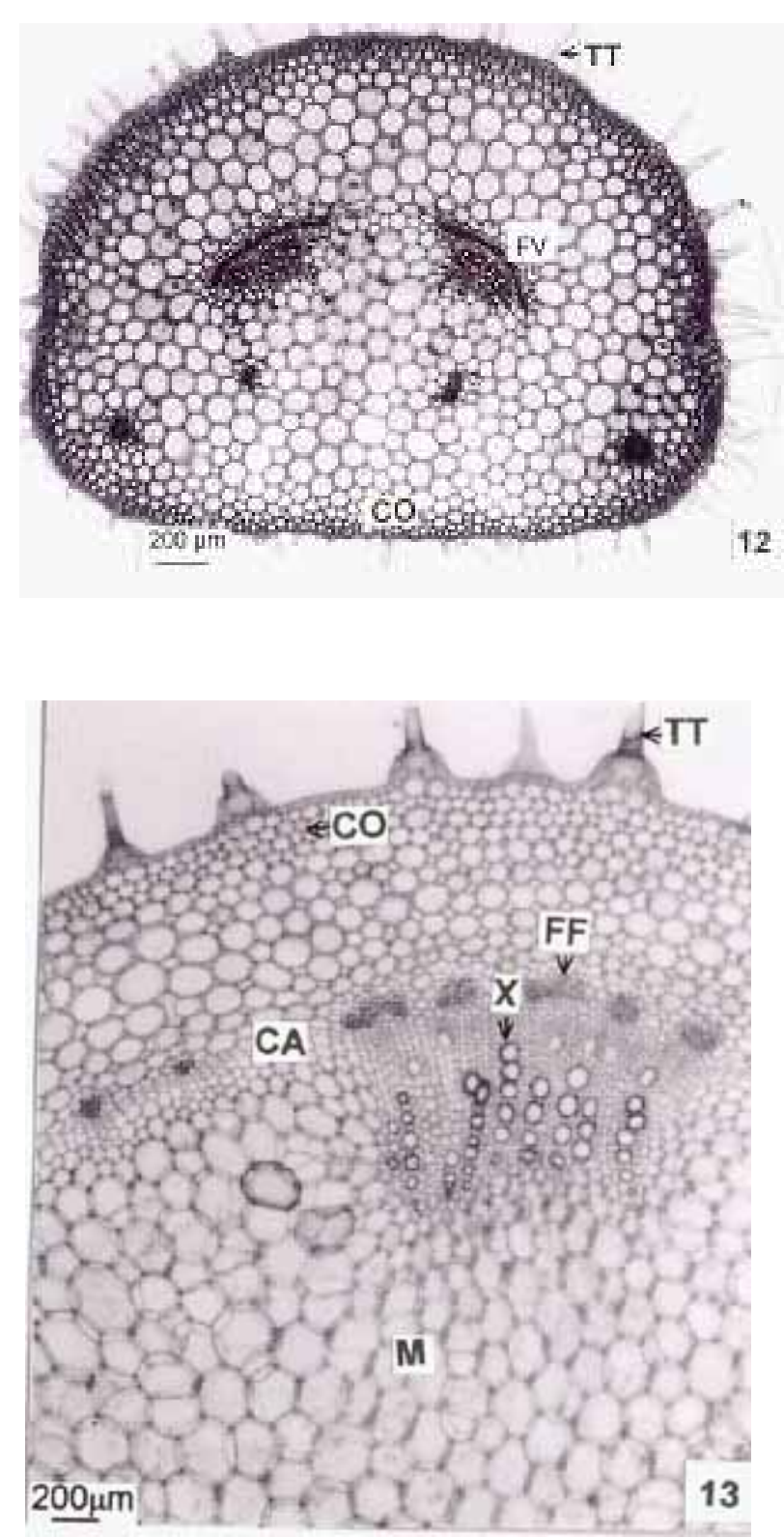

Figura 12. Malvariço (Plectranthus amboinicus (Lour.) Spreng.). Secção transversal de pecíolo: visão geral. $\mathrm{CO}$ : colênquima; TT: tricoma tector; FV: feixe vascular.

Figura 13. Malvariço (Plectranthus amboinicus (Lour.) Spreng.) Corte transversal de caule, em início de desenvolvimento secundário. TT: tricoma tector; $\mathrm{CO}$ : colênquima; $\mathrm{CA}$ : câmbio vascular; M: medula parenquimática; FF: fibras de esclerênquima floemáticas; X: xilema (elemento de vaso).

O limbo foliar de P. amboinicus apresenta um mesofilo homogêneo dorsiventral, com 1-2 camadas de parênquima paliçádido e 2-3 camadas de parênquima lacunoso (Figura 10). Há tricomas tectores unisseriados pluricelulares revestindo o limbo foliar. $\mathrm{O}$ feixe vascular colateral fechado mostra elementos de vaso de metaxilema bem visíveis (Figura 9). Há tricomas glandulares pedicelados (Figura 10). Os estômatos anomocíticos, em vista paradérmica, mostram células guarda reniformes, imersas em células epidérmicas fundamentais (Figura 11)

\section{Descrição anatômica do pecíolo}

O pecíolo mostra uma epiderme unisseriada, formado por células muito compactadas; os mesmos tricomas tectores pluricelulares visualizados no limbo foliar são visíveis no pecíolo (Figura 12). A região cortical e medular estão preenchidas por parênquima comum, com meatos. Não foram visualizados cristais de oxalato de cálcio. O feixe vascular apresenta estrutura colateral fechada (Figura 12). Pequenos feixes em formação estão presentes nas 2 extremidades do pecíolo (Figura 12).

\section{Descrição anatômica do caule}

O caule apresenta 2-3 camadas de colênquima angular, abaixo da epiderme unisseriada, formada por células diminutas. Tricomas tectores, já descritos no limbo foliar, estão presentes (Figura 13). As fibras esclerenquimáticas de floema primário formam discretas calotas, acima do floema secundário (Figura 13). É visível um câmbio vascular, formado principalmente por células radiais. O xilema secundário apresenta elementos de vaso enfileirados, cercados por fibras de esclerênquima. As regiões medular e cortical estão preenchidas por parênquima comum com meatos (Figura 13).

\section{DISCUSSÃO}

Ambas espécies possuem folhas suculentas, aromáticas, sendo que o boldo miúdo é descrito como sendo de odor nauseoso, sendo também denominado boldo gambá enquanto o malvariço possui folhas com odor semelhante ao odor do orégano. Em P. ornatus, foram visualizados, em cortes transversal e paradérmico do limbo foliar, dois tipos de tricomas glandulares, um deles pedicelado e o outro, séssil. O primeiro é análogo ao identificado por Ascensão et al. (1999), em P. ornatus. Tanto em $P$. ornatus quanto em $P$. amboinicus, as células da epiderme mostram tamanho diminuto e morfologia compacta, sendo revestidas por uma cutícula lisa e delgada. A adaptação xerofítica, em ambas as espécies, consiste na suculência do limbo foliar e pecíolo, além dos tricomas tectores (Fahn, 1990).

A disposição dos estômatos na epiderme, bem como sua classificação, é similar nas duas espécies, pertencendo ao tipo anomocítico. As células epidérmicas fundamentais, visualizadas em corte paradérmico, em $P$. ornatus, possuem paredes sinuosas. O mesofilo foliar, em $P$. ornatus, é homogêneo ou isodiamétrico. Em $P$. amboinicus, ocorre diferenciação entre parênquima paliçádico e lacunoso.

Os pecíolos das 2 espécies mostram secção côncavo-convexa, em corte transversal. Os mesmos 
tricomas tectores e glandulares constatados no limbo foliar estão também presentes no pecíolo, sendo que os glandulares ocorrem em menor número.

Não foi visualizada uma periderme no caule adulto de P. amboinicus; em P. ornatus, foi constatada a presença de periderme, com um súber bem desenvolvido. Ainda em $P$. ornatus, o xilema secundário apresenta uma aparência homogênea, com poucos elementos de vaso e abundantes fibras de esclerênquima. Não foram visualizados cristais de oxalato de cálcio nos órgãos vegetativos das duas espécies estudadas.

\section{AGRADECIMENTOS}

Às Faculdades Oswaldo Cruz, pelo respaldo oferecido ao Projeto e pela bolsa concedida às estagiárias.

\section{REFERÊNCIAS}

Agra MF, França PF, Barbosa-Filho JM 2007. Synopsis of the plants known as medicinal and poisonous in Northeast of Brazil. Rev Bras Farmacogn 17: 114140

Agra MF, Silva KN, Basílio IJLD, França PF, Barbosa-Filho JM 2008. Survey of medicinal plants used in the region Northeast of Brazil. Rev Bras Farmacogn 18: 472-508.

Albuquerque IL, Machado MIL, Matos FJA 1990. Constituintes químicos micromoleculares em espécies de Coleus. XI Simpósio de Plantas Medicinais do Brasil. João Pessoa, $\mathrm{Pb}$, Brasil.

Albuquerque RL, Lima LB, Machado MIL, Silva MGV, Braz Filho R 2003. Novo diterpeno isolado das folhas de Plectranthus ornatus. $26^{a}$ Reunião Anual da Sociedade Brasileira de Química.

Ascensão L, Mota L, Castro MM 1999. Glandular Trichomes on the leaves of Plectranthus ornatus: Morphology, distribution and histochemistry. Ann Bot 84: 437447.

Alvin Jose MI, Janardhanan S. 2005. Modulatory effect of Plectranthus amboinicus Lour. on ethylene glycolinduced nephrolithiasis in rats. Indian J Pharmacol 37: 43-44.

Brandão MGL, Cosenza GP, Moreira RA, Monte-Mor RLM 2006. Medicinal plants and other botanical products from the Brazilian Official Pharmacopoeia. Rev Bras Farmacogn 16: 408-420.

Fahn A 1990. Plant Anatomy. England :Pergamon Press.

Furlan MR 1999. Cultivo de Plantas Medicinais. Cuiabá: Coleção Agroindústria.

Morais SM, Dantas JDP, Silva ARA, Magalhães EF 2005. Plantas medicinais usadas pelos índios Tapebas do Ceará. Rev Bras Farmacogn 15: 169-177.

Matos FJA 1998. Farmácias Vivas. 3 ${ }^{\text {a }}$ ed. rev. e atual. Fortaleza: Editora UFC.

Matos FJA, Alencar JW, Craveiro AA, Machado MIL 1988. Características distintivas de duas espécies de Coleus usadas em medicina popular. X Simpósio de Plantas Medicinais do Brasil, São Paulo, Brasil.

Oliveira FQ, Gobira B, Guimarães C, Batista J, Barreto M,
Souza M 2007a. Espécies vegetais indicadas na odontologia. Rev Bras Farmacogn 17: 466-476.

Oliveira RAG, Lima EO, Souza EL, Vieira WL, Freire KRL, Trajano VN, Lima IO, Silva-Filho RN 2007b. Interference of Plectranthus amboinicus (Lour.) Spreng essential oil on the anti-Candida activity of some clinically used antifungals. Rev Bras Farmacogn 17: 186-190.

Rijo P, Gaspar Marques C, Simões MF, Duarte A, Del Carmen ARM, Cano FH, Rodrigues B 2002. Neoclerodane and labdane diterpenoids from Plectranthus ornatus. J Nat Prod 10: 1387-1390.

Silva MIG, Gondim APS, Nunes IFS, Sousa FCF 2006. Utilização de fitoterápicos nas unidades básicas de atenção à saúde da família no município de Maracanaú (CE). Rev Bras Farmacogn 16: 455-462.

Villate ML, Pérez-Saad H, Pérez MDF, Sarría EG, Castillo RM, Rodrigues MTB 1999. Plectranthus amboinicus (Lour.) Spreng. (orégano francês): efecto antimuscarínico y potenciación de la adrenalina. Revista Cubana de Plantas Medicinales 1: 29-32.

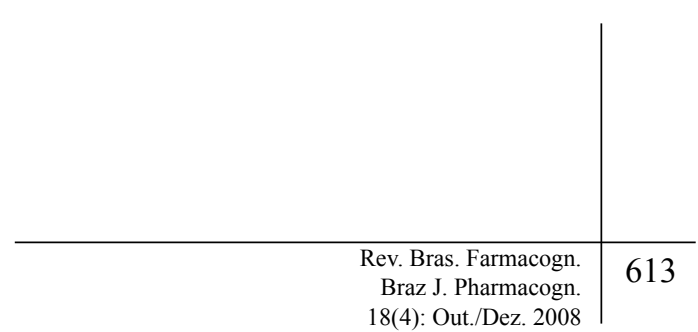

